\title{
CORRIGENDUM
}

\section{Retention rates and weight loss in a commercial weight loss program}

CE Finley, CE Barlow, FL Greenway, CL Rock, BJ Rolls and SN Blair

International Journal of Obesity (2007) 31, 394. doi:10.1038/sj.ijo.0803559

Correction to: International Journal of Obesity 2007; 31, 292-298. doi: 10.1038/sj.ijo.0803395

In the above publication the authors have noticed they have not stated they have a conflict of interest. This sentence is shown here.

\section{Conflict of Interest}

FL Greenway, BJ Rolls, and SN Blair are current members of the Jenny Craig Medical Advisory Board. CL Rock is a former member of the Board.

The authors would like to apologise for this mistake. 